\title{
TRANSFORMATION OF TRADITIONAL SAFETY
}

SHOES MANUFACTURER IN THAILAND

WITH A DEVELOPMENT OF PRODUCTION

TRACKING SYSTEM

Chawalit Jeenanunta

\author{
NUCHJARIN INTALAR KWANCHANOK CHUMNUMPORN \\ CHAWALIT JEENANUNTA APINUN TUNPAN
}

\begin{abstract}
School of Management Technology, Sirindhorn International Institute of Technology, Thammasat University, Thailand ORCID 0000-0002-1932-9776

Corresponding author: e-mail: chawalit@siit.tu.ac.th
\end{abstract}

Nuchjarin Intalar

\begin{abstract}
A B S TR A C T
There are many digital transformation challenges going forward towards Industry 4.0 in Thailand, especially for the traditional manufacturing firms that have been operating without digital technologies. The paper presents a case study of a safety shoe manufacturer, CPL Group Public Company Limited, adopting digital technologies to transform its production system of 40 years. It presents a conceptual design for production tracking based on loT technologies for productivity improvement. This research uses inductive case study research design by interviewing executives and participating in the digital tracking development project using loT sensors and image processing. The findings show the key success factors of digital transformation in manufacturing, strategies required for development, and the conceptual design of the production tracking system.
\end{abstract}

KEY WORDS

digital transformation, manufacturing, loT, production tracking, footwear industry

10.2478/emj-2021-0033
Department of Computer Science, Faculty of Science and Technology,

Thammasat University, Thailand ORCID 0000-0003-4293-0604

Kwanchanok Chumnumporn

School of Management Technology, Sirindhorn International Institute of Technology, Thammasat University, Thailand ORCID 0000-0003-4429-1674

Apinun Tunpan

SMART Sense Industrial Design Co., Ltd., Bangkok, Thailand

\section{INTRODUCTION}

Many firms have been moving toward digital transformation (DT), which refers to using new digital technologies to enable major business improvements (Fitzgerald et al., 2014). Industry 4.0 includes the digi- talisation of the production concept, the integration of learning machines, communication objects, and autonomous robots to create new avenues of production (Valenduc \& Vendramin, 2017). It consists of interoperability, virtualisation, flexibility, real-time

Intalar, N., Chumnumporn, K., Jeenanunta, Ch., \& Tunpan, A. (2021). Towards Industry 4.0: digital transformation of traditional safety shoes manufacturer in Thailand with a development of production tracking system. Engineering Management in Production and Services, 13(4), 79-94. doi: 10.2478/emj-2021-0033 
availability, automation, service orientation, and energy efficiency (Perales et al., 2018). Examples of Industry 4.0 technologies are Cyber-Physical Systems (CPS), Internet of Things (IoT), Big Data, Industry Automation, Artificial Intelligent (AI), Cloud Computing, Cybersecurity, Robotic Process Automation, Intelligent Robotics, and Human-Computer-Interaction (HCI) (Baena et al., 2017; Himang et al., 2020; Hofmann et al., 2019; Peruzzini et al., 2017; Siderska, 2020). These technologies aim to connect the physical and the virtual worlds with the intelligent flow of the workpieces machine-by-machine in a factory, in which machines communicate in real-time (Alcácer \& Cruz-Machado, 2019). The flexible and collaborative system can upgrade the factory to be more intelligent and more adaptive, allowing to make the best decision when dealing with industrial problems (Peruzzini et al., 2017).

Industry 4.0 presents a challenge for the manufacturing industry to adopt digital technology and create more efficient and effective production processes. It is an extremely challenging process because a firm needs to formulate new strategies that align with its culture and workflow. Employees are mostly afraid of being replaced by robots or AI. A firm needs to gradually change people's mindsets to embrace technologies and the new working environment. Many firms have adopted new technologies to improve production processes, such as $3 \mathrm{D}$ printing, RFID, robots to track production, increase productivity, and reduce costs in the long term (Bertola \& Teunissen, 2018). However, it is not easy to fully integrate digital technologies in the production process in a labour-intensive industry. The rapid digital transformation in manufacturing can cause problems, such as employee learning curve, resistance, and overwhelming data. Some firms invest in modern technologies, such as IoT, CPS, or humancomputer interaction systems, just because they think digital transformation is investing in technologies. They did not know how to utilise and properly implement them fully. Manufacturing has a complex adaptive system that involves adaptive interaction between humans and machines (Jones et al., 2021; Miller, 2016).

This paper presents a case study of a safety shoe manufacturer in Thailand adopting modern digital technologies for production tracking and defect detection using IoT sensors and image processing. It presents the conceptual design and development of the production tracking system for the safety shoe products. The project aims to improve productivity, increase accuracy by providing real-time production processes, and identify bottleneck processes. Furthermore, this paper shows the key DT success factors of the factory. This paper contributes to the literature on digital transformation in the manufacturing industry by providing practical methods and guidelines for firms to adopt digital technologies and improve productivity.

\section{LITERATURE REVIEW}

Automated machinery and digital and innovation technologies are important to the development of a Smart Factory. The digital transformation concept is widely discussed in different definitions (Issa et al., 2018; Jones et al., 2021; Mahmood et al., 2019). Vial (2019) developed a working definition of digital transformation as "a process that aims to improve an entity by triggering significant changes to its properties through combinations of information, computing, communication, and connectivity technologies" (Vial, 2019, p. 118). Kutnjak et al. (2019) showed a literature review of digital transformation across industries, indicating that industries have implemented modern technologies to improve production and work processes, called a smart factory. Industry 4.0 technologies like CPS, IoT, AI, Big Data, Cloud Computing, and HCI enable seamless data integration, virtual reality, and an automation system (Himang et al., 2020; Peruzzini et al., 2017; Mokhtar et al., 2020; Siderska, 2020).

Kane et al. (2015) argued that digital transformation was not only about adding technology but also more about changing aspects of processes, culture, individual mindsets, and strategies. Paulk et al. (1993) developed the capability maturity model to assess and evaluate the development of software systems, projects, human resource management, and IT governance. Issa et al. (2018) defined four maturity levels. Level 1 has no Industry 4.0 or only ad-hoc, meaning that no person is responsible for Industry 4.0 or digital technologies. Level 2 is the departmental level, at which DT is being implemented on a departmental or shop floor level. However, the activities are not synchronised. Level 3 is the organisational level, meaning that DT is implemented in the whole organisation. All departments are involved in vision and digital strategy formulation. Level 4 is the interorganisational level, meaning that DT is implemented with overall supply chain partners.

The main objectives of firms to adopt DT are efficiency, productivity, and integrating suppliers and 
customers in their value chain (Baird \& Raghu, 2015). Implementing DT required digital strategies and alignment with the whole organisation (Hess et al., 2016; Kane et al., 2015). Therefore, DT is the adoption of digital technologies (combinations of information, computing, communication, and connectivity) to radical internal and external change processes and then evolving into an implicit transformation of the organisation, requiring a holistic approach (Schweer \& Sahl, 2017). However, it is difficult to fully integrate digital technologies in the entire life cycle of products, especially for micro, small and medium enterprises (MSMEs).

Borangiu et al. (2019) stated that "the digital transformation of manufacturing envisaged by Industry 4.0 is based on the paradigm of 31 technological advances: (1) Instrumenting manufacturing resources (e.g., machines and robots), products (e.g., product carriers and subassemblies), and environment (e.g., workplaces and lighting); (2) Interconnecting orders, products/components/materials, and resources in a service-oriented approach using multiple communication technologies such as wireless, broadband Internet and mobile. (3) intelligent decision making in the manufacturing value chain based on ontologies and digital twins - digital models of manufacturing resources, processes and products extended in time, space and operating context, new controls based on ICT convergence in automation, robotics, machine vision, agent-based control, holonic organisation, data science, machine learning, and implementing frameworks: Multi-Agent Systems (MAS), Cloud services, and SOA, and novel management of complex manufacturing value chains (supply, production, delivery, after-sales services) in virtual factories" (Borangiu et al., 2019, p. 151-152).

There is no one right solution to conduct digital transformation. Many firms are ready to engage with digital transformation, but they are uncertain of how to change. A major barrier of digital transformation is the lack of an effective strategy, technology disruption, strategic alignment, data insufficiency and unreliability, high investment, inadequate knowledge and skill, and challenges in value-chain integration (Borangiu et al., 2019; Mahmood et al., 2019; Vogelsang et al., 2019; Gajdzik et al., 2021; Nwaiwu et al., 2020). Hence, many firms slowly adopted modern technologies step by step to synchronise the interaction between humans and machines and conduct trial-and-error exercises. Firms and employees need to find the root cause and propose solutions that fit their circumstances. They tend to use the widely used technologies like Radio Frequency Identification (RFID) for production tracking and production robots to optimise speed and precision (Bevilacqua et al., 2017; Chen $\& \mathrm{Tu}, 2009$; Ding et al., 2018). The main implementation objectives are to measure current performance in real-time and identify bottlenecks and losses in the operations (Stoldt et al., 2018). Ding et al. (2018) developed a prototype using RFID devices in each job-shops and a transportation vehicle to collect realtime production and transportation data in a printing machinery company. Data were processed to monitor production progress and states. Bevilacqua et al. (2017) proposed an optimisation process for the footwear production and reengineering the production planning using the IDEF0 approach and (RFID). However, it was the TO-BE map to introduce a new production scheduler and RFID technologies. The RFID provides a solution for logistical tracking of inventory or equipment (Bevilacqua et al., 2017). Chen and Tu (2009) showed the prototype of agentbased manufacturing control and coordination system. This system used ontology and RFID technology to monitor and control and track dynamic production flows of mass customisation manufacturing processes. Musikthong and Chutima (2020) presented a development plan of machinery and technologies to support digital transformation in organisations, such as manufacturing information, machinery integration, security track trace, and RFID system for production and inventory management systems.

The next step is data integration between tools, machines, and factory ICT systems, which involve data acquisition, connection, preparation, conversion, and analytics. The digitalisation of production systems requires the availability and connectivity of data and ICT systems. Many studies have proposed approaches to improve manufacturing systems using digital technologies. However, most of them cannot deal with real-time data that can be effectively analysed and used by web-based applications and services (Huang et al., 2009; Monostori et al., 2016).

CPS enables the horizontal and vertical integration of the end-to-end digital integration (Ding et al., 2018). CPPS includes the integration of computing technologies, ICT, and manufacturing science and technologies (Wright, 2014). It is characterised by intelligent and autonomous interactions among CPS objects and their environment using IoT, responsiveness to changes, and integration of physical resources (Atzori et al., 2010; Monostori et al., 2016). CPPS is connected within and across all levels of the production and logistics network. Its three main characteris- 
tics are intelligence, connectedness, and responsiveness (Monostori et al., 2016). CPPS has two main functional components: advanced connectivity to ensure real-time data acquisition and analytics and computational capabilities (Monostori et al., 2016). Previous studies have discuses CPS, IoT, and cyber-physical production systems (CPPS) (Dafflon et al., 2021; Monostori et al., 2016; Wright, 2014). Zhao et al. (2020) adopted collaborative tracking using IoT, edge computing technology, and supervised learning of genetic tracking methods to track and locate a material trolley in real-time at the airconditioner manufacturer in China. Jagtap et al. (2019) adopted an automated and real-time system based on IoT concepts, image processing, and load cell technologies to measure the overall amount of waste and the reasons for waste generation in realtime in the potato processing industry in the United Kingdom.

A video camera captured images to identify the damaged, unusable potatoes. A digital load cell measured their weight. The Convolutional Neural Network (CNN) was applied to identify a potential reason for potato waste generation. The real-time data helped workers in the production, transportation, and processing of potatoes to identify various causes of waste generation.

Jagtap and Rahimifard (2019) presented the design and IoT application to monitor and capture food waste data in real-time in the ready-meal factory, the United Kingdom. Nemec et al. (2003) presented the automation of the shoe lasting process using a commercial lasting machine, a vision-guided last positioning machine, and an industrial robot to increase productivity and reliability of the production. However, they only focused on the lasting process.

Many factories are developing and enhancing their capabilities approaching Industry 4.0. They focus on the production tracking system as one of the Industry 4.0 activities; however, a study related to this issue is limited (Minoufekr, Driate, \& Plapper, 2019; Zhong et al., 2013; Zhang \& Sun, 2013). It improves productivity, monitors workflow, detects bottlenecks, and reduces production time. Physical objects can be tracked using sensor and RFID technologies (Minoufekr, Driate, \& Plapper, 2019). Minoufekr, Driate, and Plapper (2019) showed the IoT and RFID solution for SME manufacturing to track the production chain. Each workstation was equipped with RFID scanners to record activities and the product flow. The system displayed a real-time status of the assembly line. The production efficiency increased from $62.63 \%$ to $87.50 \%$. Several challenges arise while implementing the production tracking system. Zhong et al. (2013) proposed an RFID to monitor a real-time manufacturing execution system for mass customisation production. Nevertheless, it could not support the dynamic change of manufacturing processes. Zhang and Sun (2013) proposed the architecture of an RFID-enabled customised/personalised production based on multi-agents for CPPs, which consisted of five elements: manufacturing cloud, central node (workshop gateway), local wired/wireless network, shop-floor workstations and parts/ materials. The local wired/wireless network connected the central node and workstations. RFID tags were mounted on (key) parts. Each station was equipped with RFID readers to read the identity from the tags. This system could track manufacturing objects and monitor the shop floor.

Shoe production is labour-intensive manufacturing. It requires skilled labour in many processes, such as inspection. The adoption of full automation in this industry is low (Nemec et al., 2003). There are several perspectives of research in the footwear industry, such as productivity improvement, sequencing problem, production planning, scheduling problem, automation of planning, production, and distribution processes (Calderón-Andrade et al., 2020; CastilloCastañeda et al., 2021; Jimeno-Morenilla et al., 2021; Nemec et al., 2003; Sadeghi et al., 2021). CastilloCastañeda et al. (2021) adopted the lean concept to increase productivity and reduce reprocessing. Sadeghi et al. (2021) presented an optimisation model for a mixed-model assembly line sequencing problem. Zangiacomi et al. (2004) applied a finite capacity scheduler integrated with new software based on the Analytical Hierarchy Process decision support system to solve a production planning and scheduling problem for mass customisation systems. Dang and Pham (2016) applied Discrete Event Simulation (DES) to design a footwear assembly line with uncertain task times and parallel workstations to maximise the performance of the assembly line. Tran et al. (2021) proposed a concept for a low-cost integrated automation system in footwear SMEs in Vietnam.

In Thailand, to the best knowledge of the authors, there is no case study of digital technologies implementation in the production line of a shoe factory. Extant research focused on footwear design strategies (Adulyanukosol \& Silpcharu, 2020), which is not relevant to production tracking. Case studies about implementing IoT and image processing in produc- 
tion tracking are limited. Many firms are ready to invest in modern digital technologies with limited budgets but do not know how to start. This paper presents a production tracking system designed using IoT sensors and image processing to track the production process and count good and failed products at the safety shoe factory to demonstrate how to improve the production process. IoT sensors collect shop floor data, integrate it from several machines, and display it on the system monitor in real-time. Moreover, this paper discusses the key success factors that facilitate DT in the factory.

\section{RESEARCH METHODS}

This paper conducted qualitative research by using an inductive case study. The interview was conducted onsite, and the duration was approximately two hours. A site visit was organised to observe operations in the production line for three days. The team participated in designing and developing the digital tracking solution using IoT sensors and image processing to count the number of passed and defective finished goods. An open-ended interview was used to iteratively gather information and investigate how the firm utilised digital technologies to transform the production line to yield meaningful insight (Nowell et al., 2017). the interview involved the CEO of CPL Group Public Company Limited (hereafter referred to as CPL) and the CTO of Smart Sense Industrial Design Company Limited (hereafter - Smart Sense). Smart Sense is a consulting, engineering, and IoT system service provider and the partner for hardware design and support in this project. The interview focused on the progress of the digital tracking development project using IoT sensors and image processing.

\section{RESEARCH RESULTS}

\subsection{COMPANY PROFile}

CPL is a major safety shoe manufacturer in Thailand under the "PANGOLIN" brand, the market leader in Thailand for over 25 years. On 27 January 1994, CPL registered the company with the capital of THB 180 million by Charoensin Family, Pan Oversea Cooperation, and Lien Dah Ltd. On 19 December 1994, the company transformed into a public company limited by listing on the Stock Exchange of
Thailand named "CPL Group Public Company Limited".

CPL manufactures and distributes leather products, personal protective equipment and renders the tanning service. Its business consists of three main parts: 1. Finished Leather Business, 2. Tanning Service Business, and 3. Safety Shoes and PPE. This study focuses on safety shoe production. Its products have been used by many sectors of industries nationwide and exported to various countries. Examples of its customers are Thai Honda, Thai Toyota, Charoen Pokphand, Siam Cement Group, and PTT oil.

In 2001, CPL expanded the business by a joint venture with three companies in China involved in the tannery industry and shoe factories. The tannery named "C.P.L. International Company Limited" was opened in Guangzhou, China, to support customers' purchase orders in China. Currently, this factory was terminated, and it is in the process of business restructuring. Recently, a business discussion was initiated with a new potential investor in China.

In 2016, the company invested with a business partner in Hong Kong and established a company named "Integrated Leather Business Company Limited" that engages in the import and sales of leathers. The company held $40 \%$ of total registered shares because the company saw the potential opportunities in the leather business and reduced the restrictions on the grade of leather that will be used in the production process.

The safety footwear accessory brand PANGOLIN was the first to receive certification according to the standard TIS. 523-2558, Standard Quality Management System ISO 9001: 2008 by Bureau Veritas. It has the highest market share in the safety shoes and safety equipment market in Thailand. There are three groups of safety shoe products: low, medium, and premium. The low group focuses only on durability. The medium group focuses on durability and comfort. The premium group uses higher material quality. It is more durable, comfortable and has beautiful shapes and many colours.

\subsection{Production process}

Fig. 1 shows the five main manufacturing process flows.

- Cutting process. This process uses manual cutting and semi-automation cutting machines to cut leather and material into different patterns for the upper. After that, operators conduct QC before sending it to the next process. 


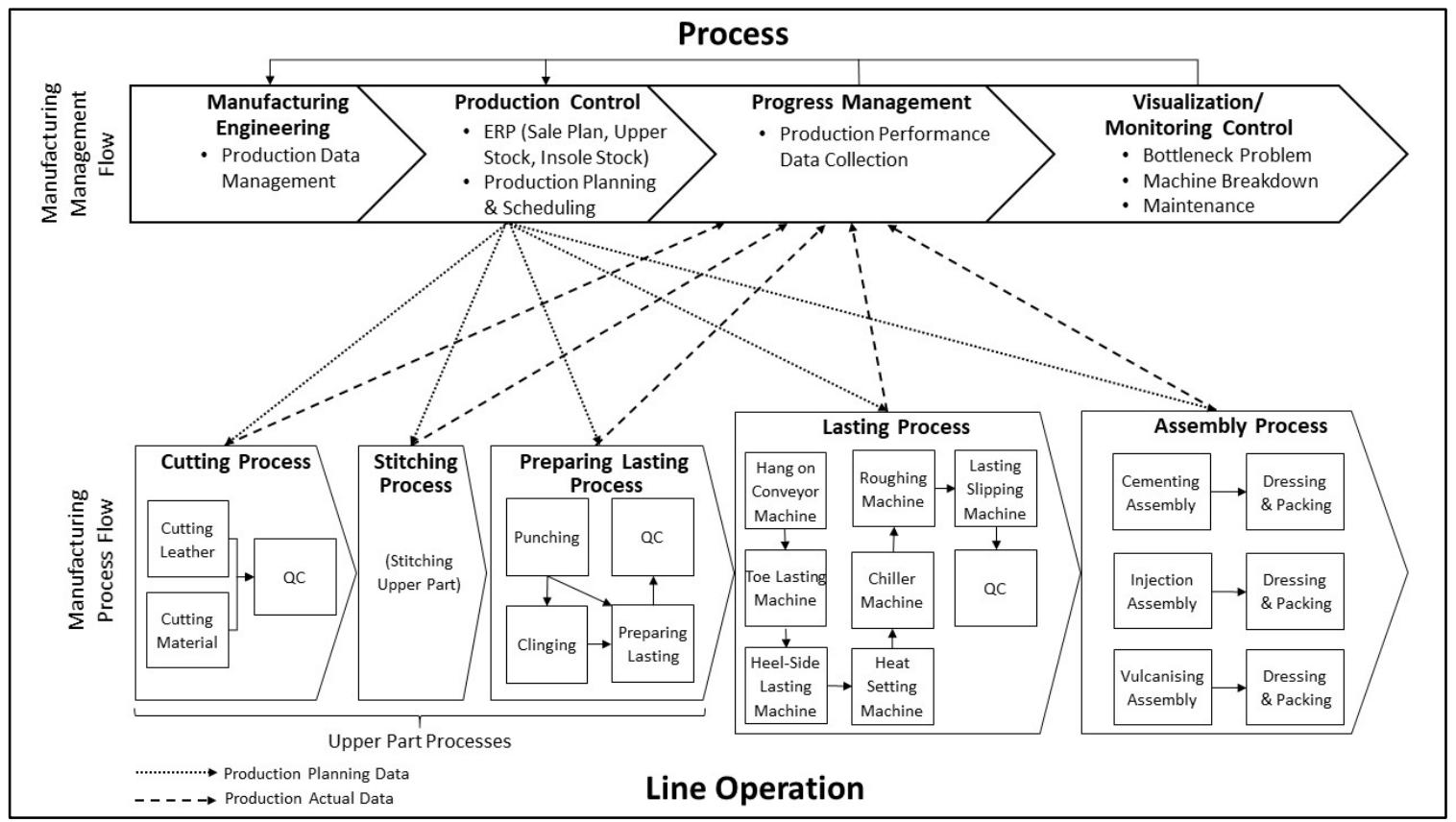

Fig. 1. Line operation for safety shoes

- Stitching process. Workers use a sewing machine or computerised sewing machine to stitch upper parts together according to a pattern.

- Preparing lasting process. Workers use machines for punching, clinging, and detail sewing to prepare upper parts for the lasting process (i.e., some detail sewing).

- Lasting process. This process uses a combination of manual, semi-automated, and automated machines. There are two types of upper: Stretching and Strobel, which are processed in parallel production. There are eight subprocesses in this workstation. Parts are hung on the conveyor machine to the lasting machine. After parts are fed into the machine, the shoe lasting machine glues the shoe upper and shoe last and sends to the toe lasting process for gluing. There are two toe lasting machines for the left and right sides. Then parts move to the heel-side lasting machine for gluing. There are two heel-side lasting machines for the left and right heel. Then it moves to the heat setting machine to apply hightemperature steam and hot air to mould the upper for controlled periods of time to destress and relieve the residual stress from the lasting process. Then it moves to the chilling machine. The chiller machine is used after tightening the shoe to stabilise the shoe material on the block with the sole glued to reduce the processing time of the workpiece on the shoe last. Cold tempera- ture is used to stabilise leather and remove the excess moisture from the surface. Then, the parts move to the roughing machine and then to the lasting slipping machine. The last subprocess is the inspection. Inspectors conduct a quality check to ensure that the upper is appropriately sewn, the size of the upper is correct, the quarter tightening system is correct, materials for the lasting are suitable and compatible with the materials of the safety shoe.

- Assembly process. This process combines the upper with the insole. There are three assembly processes: cementing (one assembly line), injection (three assembly lines), and vulcanising (one assembly line). The cementing process has a conveyor and a semi-automated machine. The injection process uses the semi-automated machine and robot arms. The vulcanising process uses semi-automated machines. Each machine can produce only one side of the shoe. The outputs of each assembly line move through its conveyor to the dressing and packing processes. The dressing process is the final detail decoration and checks the quality of products before sending to the packing process. If the product has defects, QC staff will apply a mark to identify defective spots and separate them to another line. For the passed products, workers put Pass QC stickers on the box and pack them. 


\subsection{Problems in the CURRENT SySTEM}

The current system has no digital production planning or scheduling. Managers use their experience to order production. They use a production order sheet to identify the total number of daily productions for each safety shoe model. Mostly, the total number of productions did not finish as planned. Sometimes when there is a surge in demand, the factory fails to meet customer needs.

The current system consists of manual, semiautomated, and automated machines. However, the majority of the system is manual machines that require worker interaction. Despite implementing machines and robots in the production line, the factory has not installed any IoT devices to collect data. Managers and employees do not have real-time production status data, temperature, and the number of passed and defective shoes. The plant manager and operators cannot see the real-time temperature at heat setting and chiller machines. Moreover, the machine status (on-off, breakdown, maintenance) cannot be tracked, leading to insufficient control management and cannot help managers identify bottlenecks in the system, especially in the lasting process with many sub-processes. When a machine is down or stops working, managers or operators do not get a system alert. Operators need to inform the manager when they see it happen, which slows down the production and affects production planning. In addition, the production capacity cannot be maximised.

Another issue is the production tracking at the lasting workstation. There is no record of a num- ber of products in and out from the system. Operators have to record data manually, which causes data inaccuracy and difficulty in justifying the overall equipment effectiveness (OEE). The last issue is the lack of passed/defective product recording. In the current system, inspectors at the packing workstation need to check each shoe's defects in the box manually, separate defected from passed products, and count them box by box.

\subsection{DESIGN AND DEVELOPMENT OF PRODUC- TION TRACKING SYSTEM}

This paper presents a conceptual design and development of the production tracking system by adopting the IoT sensors and video camera to track the production flow starting from the lasting process to the assembly process (Fig. 2). This system also includes real-time data display and monitoring control.

There are three types of IoT box prototypes: IoT box for temperature tracking, IoT box for machine status tracking, and IoT box as a gateway to connect the data from the shopfloor, cameras, and the software part. They were installed at the lasting, cementation, PU2003 injection, PU2001 injection, and vulcanising workstations to cover the critical areas. The IoT box was not installed at the PU1983 injection workstation because it produces special products that have low demand each year.

Before the digital transformation, managers and operators could not see the current temperature in the heat setting, chiller machine, and gluing process

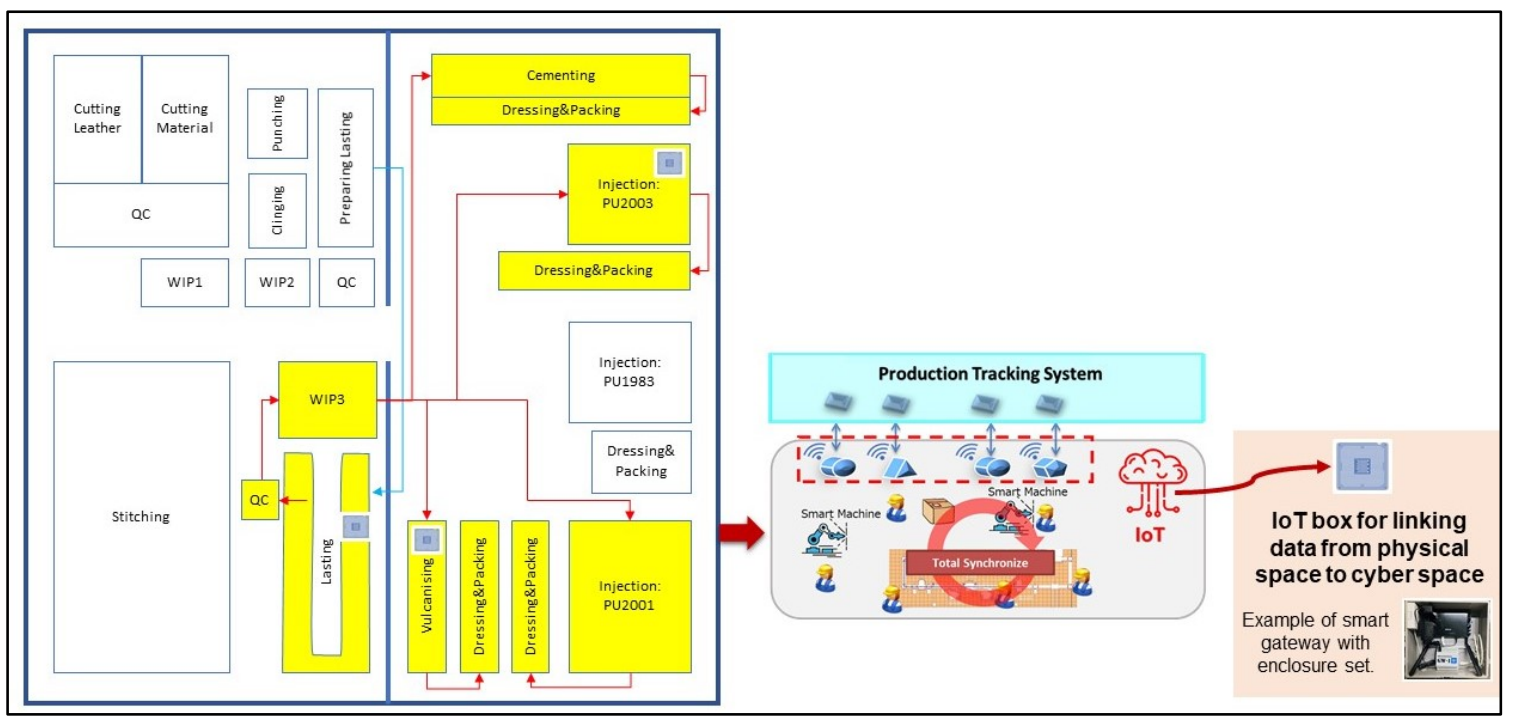

Fig. 2. Conceptual design of the production tracking system 
at the lasting station. Therefore, six IoT temperature sensors were used at the lasting workstation to improve productivity and show the real-time temperature at each station (Fig. 3). Two sensors were installed at three stations: the heat setting, chillers machine, and the gluing process. Temperature control is important for these processes to produce a quality product.

The QR code is used to update product movement and status. The batch QR code contains the Batch ID, date of the job order, the station, the quantity for the lot, the pattern insole, the group, the SKU number, the shoe size, and the quantity. Operators move the WIP in batch (Fig. 4). Once the batch is ready, an operator scans the $\mathrm{QR}$ code for checking in and confirms the production number on the tablet screen. The system records the production time for each batch. Once the production process of each batch begins, the input buffers are divided into each basket by four pairs, consisting of two pairs of stretching and Strobel. The stretching group needs to go to vulcanising, the PU2001 injection process, and the cementing process. The Strobel group goes to the PU2003 injection process and cementing processes.

Fig. 5 shows the process before leaving the lasting station. A QC worker checks the product quality and then scans the job order card to count the passed product. The worker must confirm each batch's num-

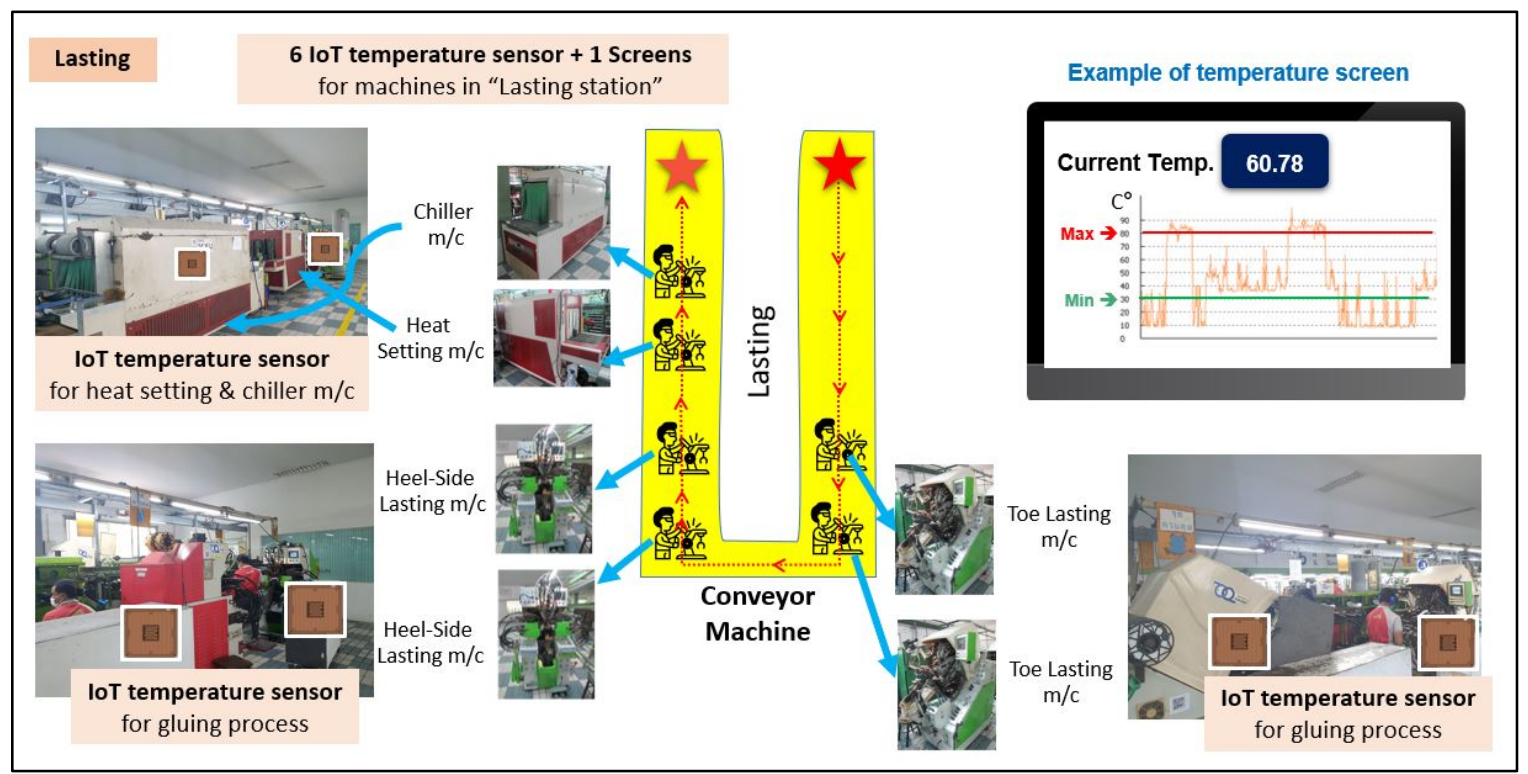

Fig. 3. Design concept of loT sensor installation at the lasting station

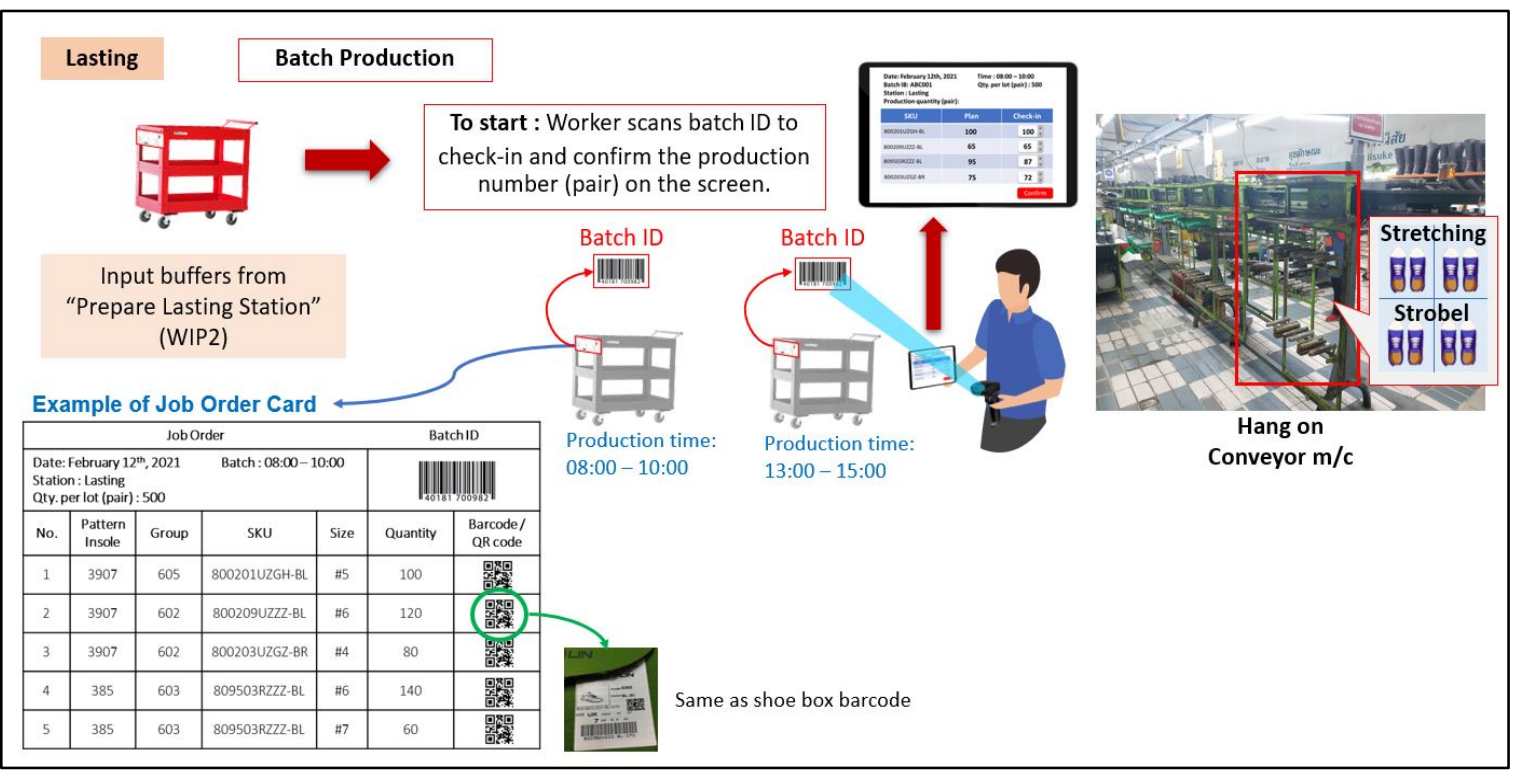

Fig. 4. Design work process at the lasting station by using the QR code and Kanban job order 


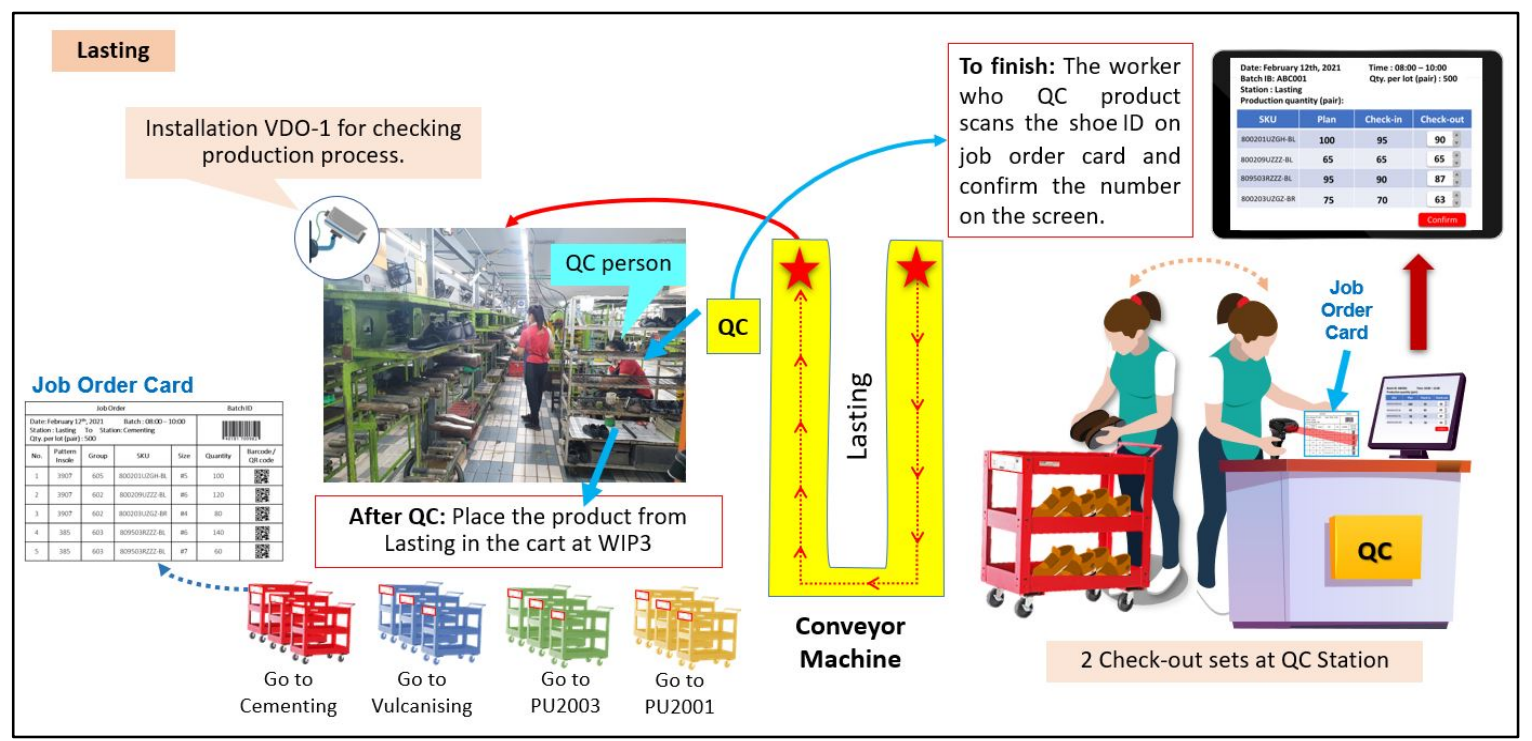

Fig. 5. Design work process of inspection at the lasting station

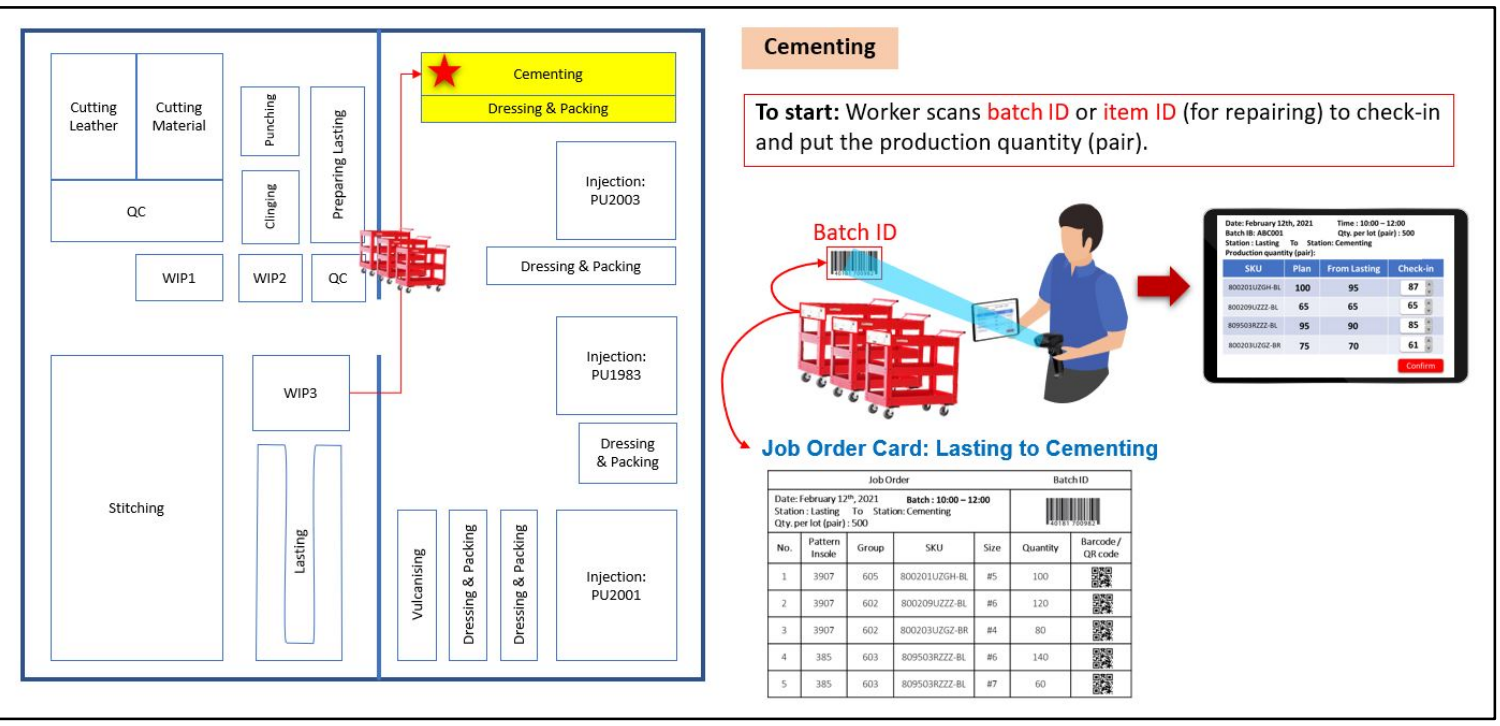

Fig. 6. Example of the production tracking system at the cementing process (check-in process)

ber of passed products before placing the passed product from a lasting station on the cart at the WIP3 station and waiting to be transferred to the assembly stations. There are four types of carts. The first cart goes to the cementing station. The second cart goes to the vulcanising station. The third cart goes to the PU2003 injection station, and the last one goes to the PU2001 injection station. A QC worker scans the QR code of each product on the job order card and confirms the total number on the computer. Then the job order card is attached to each cart. The cart is transferred to the next process. This process was observed over an installed video camera to monitor the production process.

There are four assembly stations in this production tracking system design scope: cementation,
PU2003 injection, PU2001 injection, and vulcanisation. At the check-in point of each assembly station, an operator scans Batch ID or Item ID (for repairing) to receive this order and confirm the production quantity. At the vulcanising station, a video camera was installed for defect tracking (Fig. 7).

Two injection stations are involved in the production tracking system: PU2003 and PU2001. This station uses a 6-axis spray robot, 6-axis roughing robot robotics, and PU injection machines. An injection machine has 24 sub-machines. Each submachine can produce one side of the shoe. Thus, the QR code and the IoT sensor were used to update product movement and status. These IoT sensors were installed to detect and count incoming and outgoing products from the station. Additionally, the 


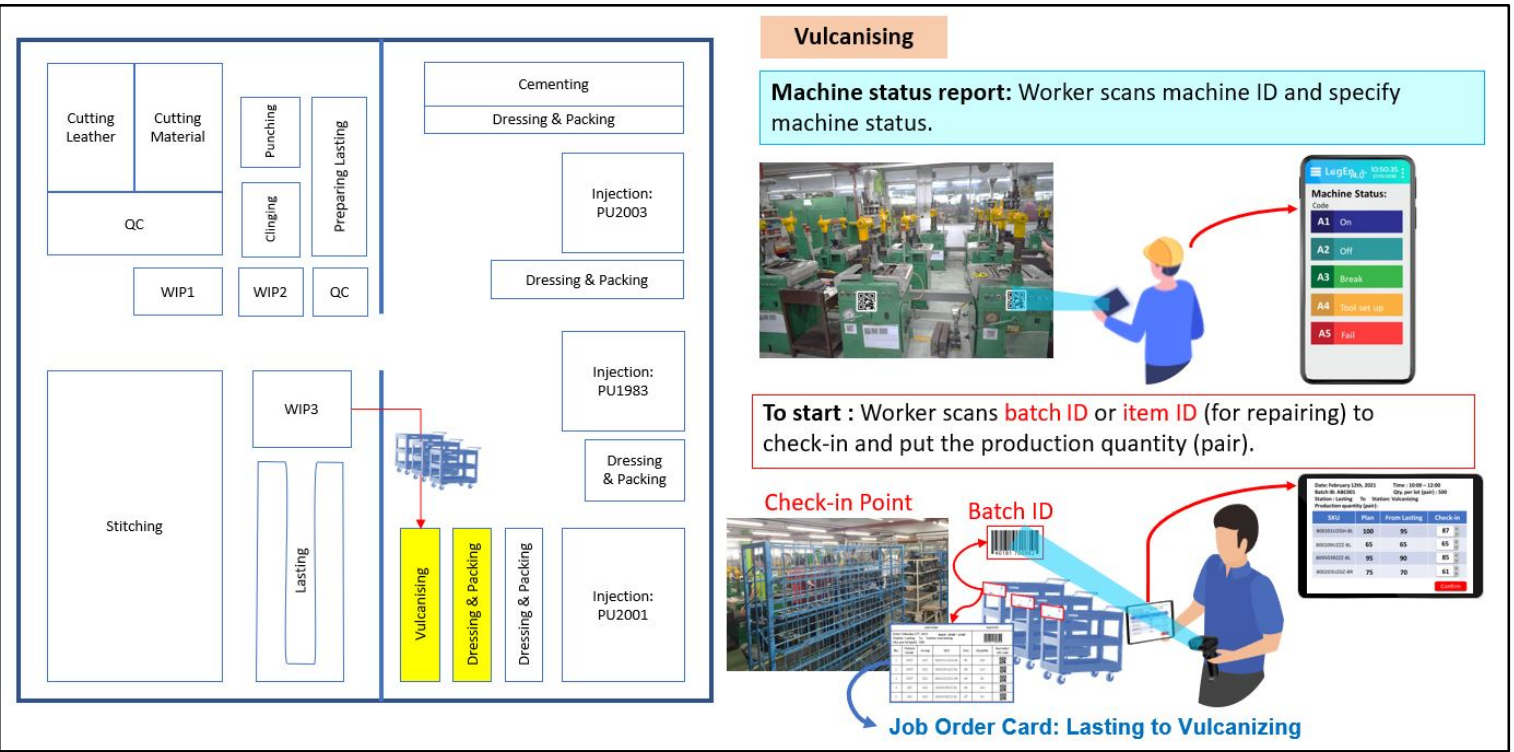

Fig. 7. Example of the production tracking system at the vulcanising process (check-in process)

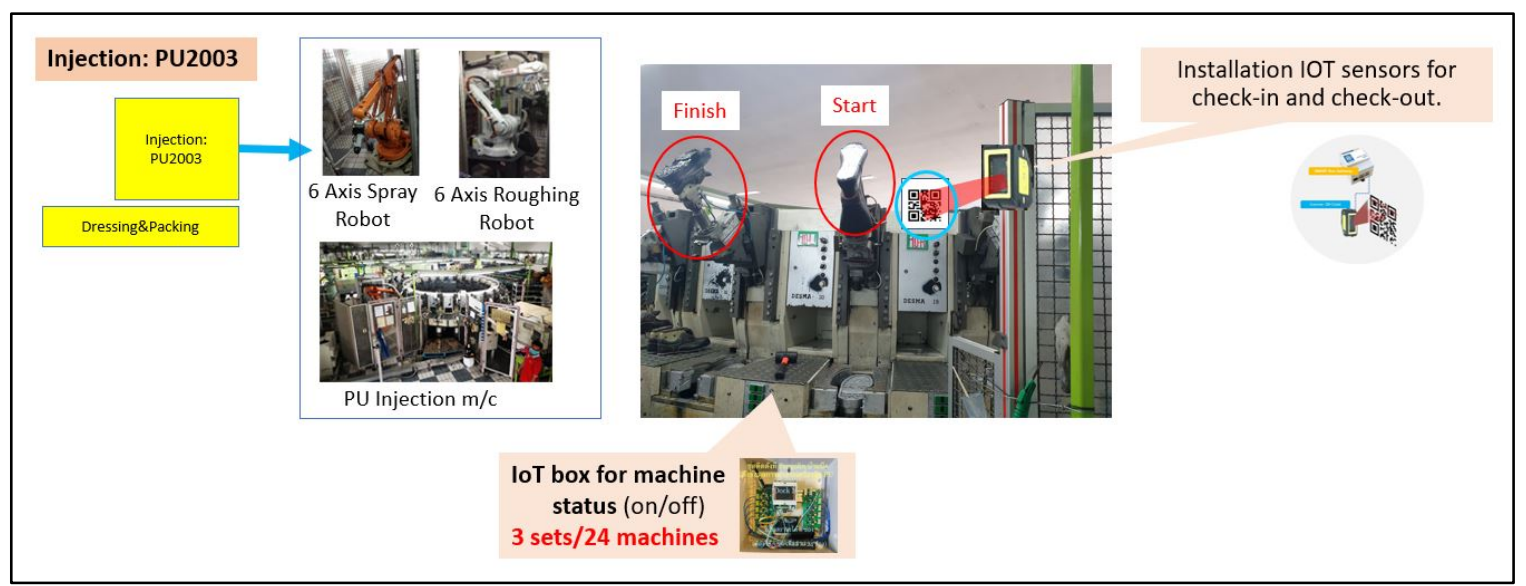

Fig. 8. Machine status tracking at the PU2003 injection process

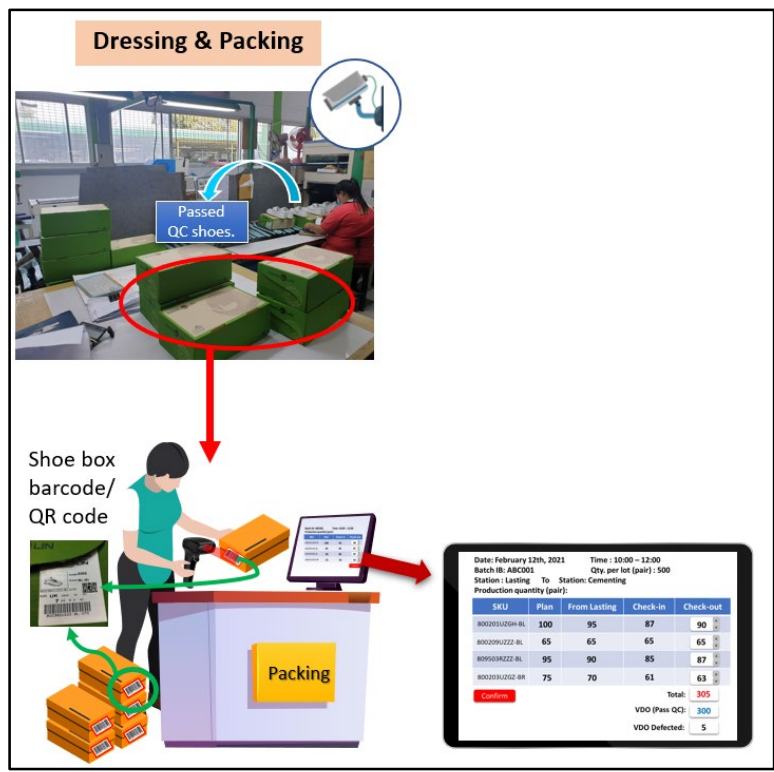

Fig. 9. Dressing and packing process 


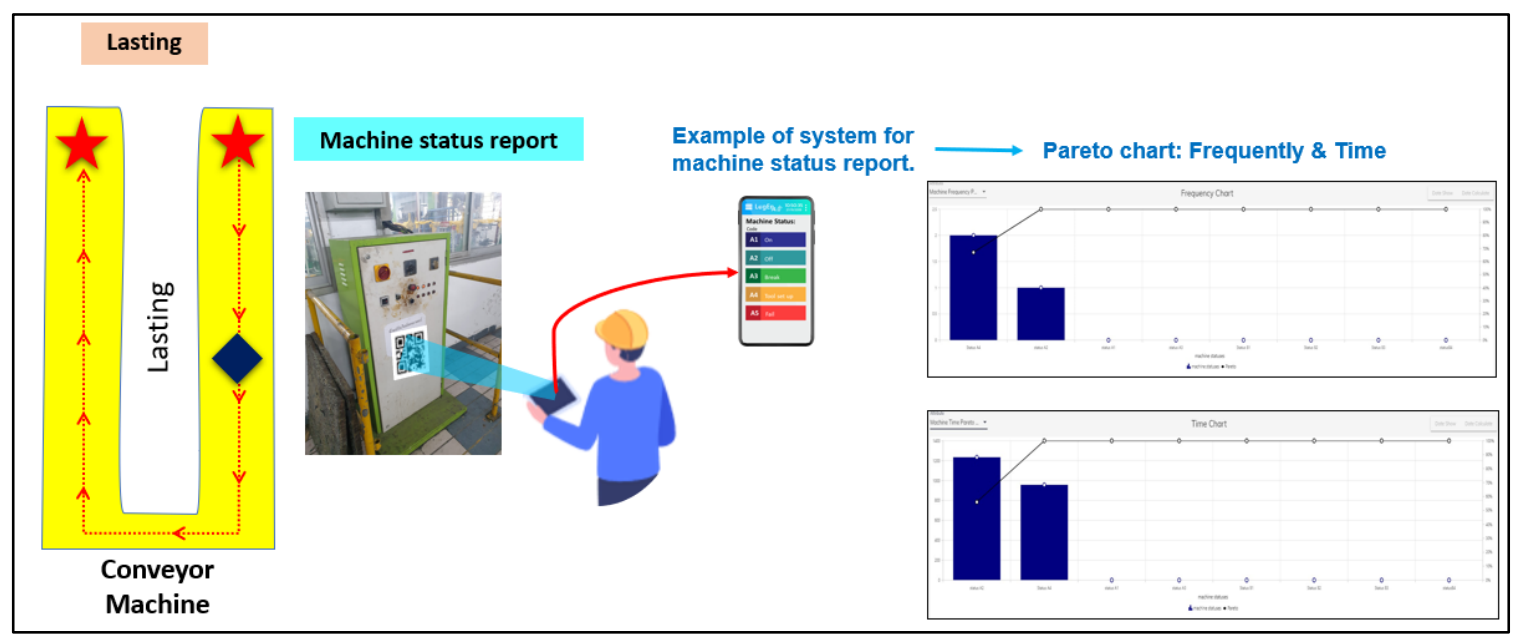

Fig. 10. Machine status manually reported system at the lasting process

three sets of IoT boxes were installed to automatically track the on-off status for 24 sub-machines. The same IoT set was installed for both PU2003 and PU2001 lines for the machine status tracking.

At the dressing and packing of each assembly station, one video camera was installed for defect tracking. Image processing was used to detect and count passed and failed products. The defects were speared for reproduction. A QC worker marks the passed sign spot-on product and sends it on the conveyor to the packing point. Then packing worker scans the QR code or the Barcode to record it into the system, then rechecks and confirms the productivity of each batch before sending it to the warehouse. All assembly stations have the same process for product check-in and check-out.

Machine status tracking is important for machine monitoring. A real-time machine status report was designed at the lasting station, injection, and vulcanising machines. IoT boxes collect the status of machines, such as on-off, breakdown, tooling changeovers, and maintenance. These data allow operators and managers to determine the machine's efficiency, condition-based maintenance, and detect the production problem in real-time.

From the above-described conceptual model, the solutions already implemented in the production processes are the installation of two sets of IoT temperature sensors at the lasting station. The team ensured that the devices were well-functioning and provided accurate temperature values. The four video cameras were installed at the beginning of the lasting process (one unit), at the lasting $\mathrm{QC}$ process (two units), and at the dressing and packing station (one unit).
This conceptual design and development of a production tracking system allow the factory to monitor the production process and performance in real-time. Moreover, it helps them to detect any breakdown, bottleneck in the processes and increase the overall efficiency.

\section{DISCUSSION OF THE RESULTS}

\subsection{DeVelopment of THE PROdUCtion TRACKING SYSTEM}

Industry 4.0 poses a significant challenge for the manufacturing firms in Thailand, especially SMEs, as the capital and resources are limited. The case study demonstrated in the previous section provides an example of the digitalisation of the safety shoe factory. The CPL has mixed machine and human interaction systems for the production processes. The production data and machine status are collected manually on paper and stored in the form of electronic files. However, the data implementation and utilisation are limited as the firm cannot visualise data and analyse it to detect a problem in real-time. Consequently, the report is inaccurate. To solve these problems, CPL gradually adopted Industry 4.0 technology to improve the production process and productivity.

CPL collaborated with Smart Sense and the university research unit to design the production tracking system using QR codes, IoT sensors, and cameras to track and collect data from the production line. The system covers the lasting, cementing, injection, vulcanising, dressing, and packing stations. The sys- 
tem design includes both hardware and software aspects. The software consists of a web application that operators use to confirm the amount of input and output in each station and the image processing recount to confirm the productivity accuracy. Another part is a real-time machine temperature monitoring, cycle time visualisation, and alert system. The software collects data from manual input and retrieves data automatically from IoT sensors. For hardware design, the architecture was designed for IoT sensor installation at a feasible location to optimise performance and minimise total cost. Video cameras were installed for image processing, a handheld scanner to scan QR codes, and tablets and monitors to display real-time data. The prototype system is under development at CPL.

In terms of process improvement, the factory has learned that the development of the production tracking system allows their employees to improve their workflow and realise the bottleneck of the current processes. Moreover, they learned how to change the adjustable layout, working position, and environment to improve the efficiency of image processing and increase accuracy.

\subsection{KEY SUCCESS FACTORS OF DIGITAL TRANSFORMATION}

As already mentioned, the implementation of digital technologies requires modern technologies, strategies, and support from management. The key success factors of this project are as follow.

1. CPL used a top-down approach to initiate digital transformation in the organisation. The company owner imposed digital strategies and created a collaborative environment to encourage employees to collaborate on projects with external experts and academics to create a knowledge and technology transfer network. This approach is in line with Vogelsang et al. (2019), who suggested that "DT as many projects cannot be executed without other companies from the network" (Vogelsang et al., 2019, p. 132). The top management approved and provided funding to support the production tracking system.

2. Since this is the first DT project in the company, the absorptive capability of employees is low. Most employees do not know how to implement digital technologies in a production line. Smart Sense and the academic team filled this gap by providing knowledge, know-how, and technologies and managing the whole project. The team created an intensive session with production line operators to investigate the root cause of the problem on the shopfloor and visited the shop floor to observe the actual operation. Once pain points and bottlenecks were identified, it was easy to convince employees that digital technologies could help them to improve productivity. The team trained employees to understand and use IoT sensors.

3. After understanding pain points and how DT could improve overall production processes, employees embraced the transformation quickly. Once they understood the project's usability, they voluntarily expressed ideas and proposed solutions from their perspective. During the system installation and development, employees provided feedback on the system's software user interface design and architecture design.

4. The pilot project helped to realise and see the whole issues of operations. The tracking system allowed detecting issues related to employee ergonomics, movement, workflow, and bottlenecks in the production processes. With the numerical and visual evidence, the plant manager solved the production at the right pain points and created a better workflow. Furthermore, the plant manager proposed adjusting the working environment on the shop floor to enhance the efficiency of the production tracking system. For example, create zoning in the conveyor to separate passed and defective shoes, create a dividing line in the defective shoe areas to enhance the detection efficiency (Fig. 11). Fig. 12 shows before and after adjustment by installing transparent partition at the lasting to prevent the camera from counting the shoes on the back shelf, which can mislead the image processing detection.

5. According to the definition of the capability maturity model developed by Issa et al. (2018), CPL has developed level three of the capability maturity readiness to embrace digital technologies. It had a vision and mission, assigned a team responsible for DT, formulated well-defined processes and support systems. DT was used to solve production problems on the shop floor level. Departments were involved in defining and imposing digital strategies. CPL adopted $5 \mathrm{~S}$ and several ISO standards to maintain and continually improve its performance and quality.

It provided in-house training to employees about warehouse management and related topics to improve productivity. The company also implemented enterprise resource planning (ERP) software and adopted robotics in some production processes. Employees also collect data manually to identify the OEE. Therefore, they gained an initial readiness for digital transformation. 


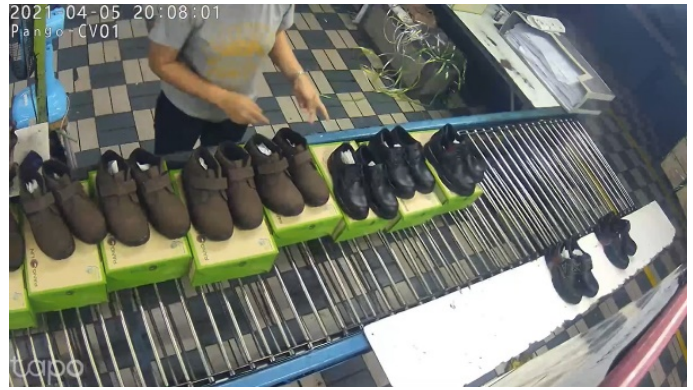

Fig. 11. Before (left) and after (right) adjusting on the conveyor

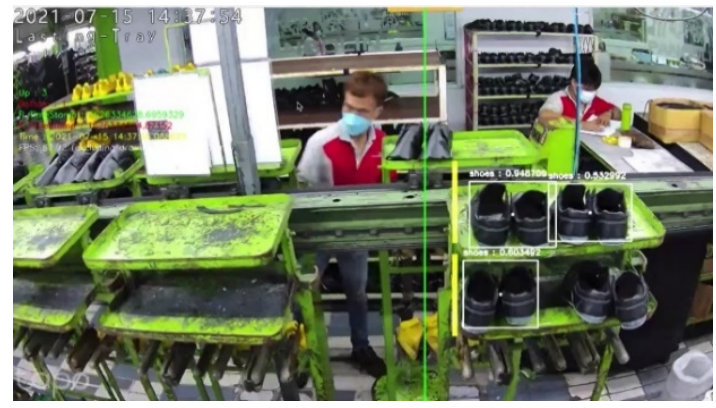

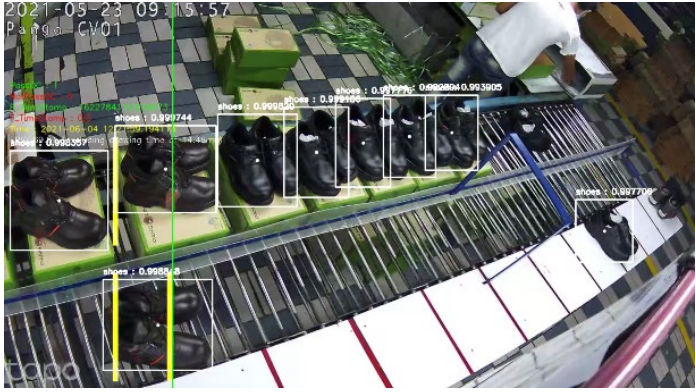

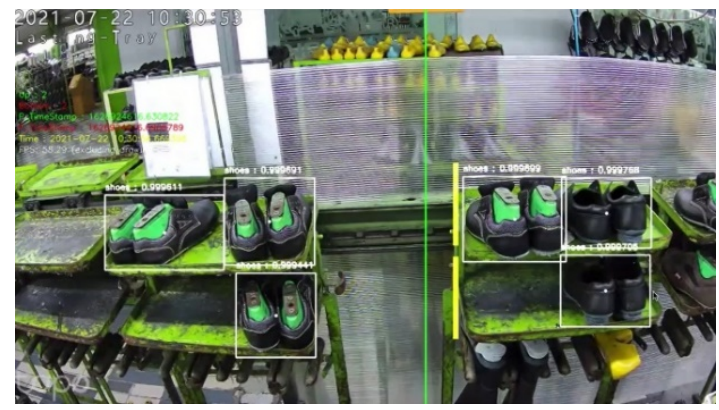

Fig. 12. Before (left) and after (right) adjusting at the lasting workstation

6. The plant manager had a background in accounting and a deep understanding of the production process. She identified root causes in the production line instantly after seeing the data from the pilot project. Moreover, she understood how to apply digital technologies to improve the system.

\section{CONCLUSIONS}

Implementing digital technologies in the manufacturing industry is challenging. Thai manufacturing gradually adopts modern technologies like CPS, IoT, and automation to improve productivity. However, the study of the implementation is limited. This paper proposed a conceptual design and production tracking prototype in the safety shoe manufacturer in Thailand. QR codes, IoT devices, and video cameras were used to perform image processing and track production status.

The system shows real-time data regarding the temperature of the heat setting machine, chiller machine, and gluing machine. Operators can monitor real-time data on the machine status, the total number of input and output from each workstation. Finally, the system can count the number of passed and defective products before packing. This system helps managers and operators to identify bottlenecks of the process, overall equipment effectiveness, and plan production.

This paper also presents the key success factors of digital technologies implementation in manufacturing. The key drivers are full support from the top management, setting digital strategies aligned with business strategies, the working environment, collaboration with experts, academics, and networks, training and managing project by experts, two-way knowledge and technology transfer, visible usability, and individual mindset. The results can be used as a guideline for developing real-time production tracking in the production line in another factory.

The limitation of this paper is that it mainly focused on qualitative analysis to define the key success factors of digital transformation and the development of the conceptual design for the production tracking system at CPL. Future research should include quantitative analysis and simulation to demonstrate practical effects achieved, such as productivity, number of defects and defective accuracy. Future research should expand the framework by using data retrieved from production tracking to create production planning and scheduling for each shoe model. A real-time data can be used to create daily, weekly, and monthly production planning and scheduling. Furthermore, data can be synchronised and used to create a simulation model to monitor production flow. 


\section{ACKNOWLEDGEMENTS}

The authors would like to acknowledge executives and staff from the CPL Group Public Company Limited and Smart Sense Industrial Design Company Limited for valuable information and insights. This research is supported by the Centre of Excellence in Logistics and Supply Chain Systems Engineering and Technology (CoE LogEn), Thammasat University.

The publication of the article for the 11th International Conference on Engineering, Project, and Production Management - EPPM2021 was financed in the framework of contract No. DNK/ SN/465770/2020 by the Ministry of Science and Higher Education within the "Excellent Science" programme.

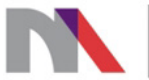

Ministry of Science and Higher Education

Republic of Poland

\section{LITERATURE}

Adulyanukosol, A., \& Silpcharu, T. (2020). Footwear Design Strategies for the Thai Footwear Industry to Be Excellent in the World Market. Journal of Open Innovation: Technology, Market, and Complexity, 6(1), 5-16. doi: 10.3390/joitmc6010005

Alcácer, V., \& Cruz-Machado, V. (2019). Scanning The Industry 4.0: A Literature Review on Technologies for Manufacturing Systems. Engineering Science and Technology, An International Journal, 22(3), 899-919.

Atzori, L., Iera, A., \& Morabito, G. (2010). The Internet of Things: A Survey. Computer Networks, 54(15), 27872805

Baena, F., Guarin, A., Mora, J., Sauza, J., \& Retat, S. (2017). Learning Factory: The Path to Industry 4.0. Procedia Manufacturing, 9, 73-80.

Baird, A., \& Raghu, T. (2015). Associating Consumer Perceived Value with Business Models for Digital Services. European Journal of Information Systems, 24(1), 4-22.

Bertola, P., \& Teunissen, J. (2018). Fashion 4.0. Innovating Fashion Industry through Digital Transformation. Research Journal of Textile and Apparel, 22(4), 352369. doi: 10.1108/RJTA-03-2018-0023

Bevilacqua M., Ciarapica F. E., \& Mazzuto G. (2017). Development of Scheduling Systems for a Shoe Factory Through IDEF0 and RFID Technologies. In R. Rinaldi \& R. Bandinelli (Eds.), Business Models and ICT Technologies for the Fashion Supply Chain. IT4Fashion 2016. Lecture Notes in Electrical Engineering, 413. Cham, Switzerland: Springer. doi: $10.1007 / 978$ 3-319-48511-9_15

Borangiu, T., Trentesaux, D., Thomas, A., Leitão, P., \& Barata, J. (2019). Digital Transformation Of Manufacturing through Cloud Services and Resource Virtualization. Computers in Industry, 108, 150-162.
Calderón-Andrade, R., Hernández-Gress, E. S., \& Montufar Benítez, M. A. (2020). Productivity Improvement through Reengineering and Simulation: A Case Study in a Footwear-Industry. Applied Sciences, 10(16), 5590-5616.

Castillo-Castañeda J., Tarazona-Lopez B., Leon-Chavarri C., Cardenas L. (2021). Productivity Improvement of a Footwear Manufacturing Company Through Lean Tools. In S. Trzcielinski, B. Mrugalska, W. Karwowski, E. Rossi, \& M. Di Nicolantonio (Eds.), Advances in Manufacturing, Production Management and Process Control. AHFE 2021. Lecture Notes in Networks and Systems, 274. Cham, Switzerland: Springer. doi: 10.1007/978-3-030-80462-6 53

Chen, R.-S., \& Tu, M. A. (2009). Development of an AgentBased System for Manufacturing Control and Coordination with Ontology and RFID Technology. Expert Systems with Applications, 36(4), 7581-7593.

Dafflon, B., Moalla, N., \& Ouzrout, Y. (2021). The Challenges, Approaches, and Used Techniques of CPS for Manufacturing in Industry 4.0: A Literature Review. The International Journal of Advanced Manufacturing Technology, 113(7-8), 2395-2412. doi: 10.1007/ s00170-020-06572-4

Dang, Q.-V., \& Pham, K. (2016). Design of a Footwear Assembly Line using Simulation-Based ALNS. Procedia CIRP, 40, 596-601.

Ding, K., Jiang, P., \& Su, S. (2018). RFID-enabled Social Manufacturing System for Inter-Enterprise Monitoring and Dispatching of Integrated Production and Transportation Tasks. Robotics and Computer-Integrated Manufacturing, 49, 120-133. doi: 10.1016/j. rcim.2017.06.009

Fitzgerald, M., Kruschwitz, N., Bonnet, D., \& Welch, M. (2014). Embracing Digital Technology: A New Strategic Imperative. MIT Sloan Management Review, 55(2), 1.

Gajdzik, B., Grabowska, S., \& Saniuk, S. (2021). Key socioeconomic megatrends and trends in the context of the Industry 4.0 framework. Forum Scientiae Oeconomia, 9(3), 5-22. doi: 10.23762/FSO_VOL9_NO3_1

Hess, T., Matt, C., Benlian, A., \& Wiesböck, F. (2016). Options for Formulating a Digital Transformation Strategy. MIS Quarterly Executive, 15(2). 123-139.

Himang, C., Ocampo, L., Obiso, J.-J., Bongo, M., Caballes, S. A., Abellana, D. P., Deocaris, C., \& Ancheta, R. (2020). Defining Stages of the Industry 4.0 Adoption via Indicator Sets. Engineering Management in Production and Services, 12(2), 32-55. doi: 10.2478/ emj-2020-0010

Hofmann, E., Sternberg, H., Chen, H., Pflaum, A., \& Prockl, G. (2019). Supply Chain Management and Industry 4.0: Conducting Research in the Digital Age. International Journal of Physical Distribution \& Logistics Management,49(10), 945-955.

Huang, G., Wright, P., \& Newman, S. T. (2009). Wireless Manufacturing: A Literature Review, Recent Developments, and Case Studies. International Journal of Computer Integrated Manufacturing, 22(7), 579-594.

Issa, A., Hatiboglu, B., Bildstein, A., \& Bauernhansl, T. (2018). Industrie 4.0 Roadmap: Framework for Digital Transformation based on the Concepts of Capability Maturity and Alignment. Procedia CIRP, 72, 973-978. 
Jagtap, S., Bhatt, C., Thik, J., \& Rahimifard, S. (2019). Monitoring Potato Waste in Food Manufacturing Using Image Processing and Internet of Things Approach. Sustainability, 11(11), 3173-3185. doi: 10.3390/ su11113173

Jagtap, S., \& Rahimifard, S. (2019). The Digitisation of Food Manufacturing to Reduce Waste - Case Study of a Ready Meal Factory. Waste Management, 87, 387397. doi: 10.1016/j.wasman.2019.02.017

Jimeno-Morenilla, A., Azariadis, P., Molina-Carmona, R., Kyratzi, S., \& Moulianitis, V. (2021). Technology Enablers for the Implementation of Industry 4.0 to Traditional Manufacturing Sectors: A Review. Computers in Industry, 125, 103390-103403. doi: 10.1016/j. compind.2020.103390

Jones, M. D., Hutcheson, S., \& Camba, J. D. (2021). Past, Present, and Future Barriers to Digital Transformation in Manufacturing: A Review. Journal of Manufacturing Systems, (in press). doi: 10.1016/j. jmsy.2021.03.006

Kane, G. C., Palmer, D., Phillips, A. N., Kiron, D., \& Buckley, N. (2015). Strategy, Not Technology, Drives Digital Transformation. MIT Sloan Management Review and Deloitte University Press, 14(1-25).

Kutnjak, A., Pihiri, I., \& Furjan, M. T. (2019). Digital Transformation Case Studies Across Industries-Literature Review. In 42nd International Convention on Information and Communication Technology, Electronics and Microelectronics (MIPRO), 20-24 May 2019, Opatija, Croatia.

Mahmood, F., Khan, A. Z., \& Khan, M. B. (2019). Digital Organizational Transformation Issues, Challenges and Impact: A Systematic Literature Review of a Decade. Abasyn University Journal of Social Sciences, 12(2), 231-249.

Minoufekr, M., Driate, A., \& Plapper, P. W. (2019). An IoT Framework for Assembly Tracking and Scheduling in Manufacturing SME. ICINCO, 2, 585-594.

Mokhtar, S. S. S., Mahomed, A. S. B., Aziz, Y. A., \& Rahman, S. Ab. (2020). Industry 4.0: the importance of innovation in adopting cloud computing among SMEs in Malaysia. Polish Journal of Management Studies, 22(1), 310-322.

Monostori, L., Kádár, B., Bauernhansl, T., Kondoh, S., Kumara, S., Reinhart, G., Sauer, O., Schuh, G., Sihn, W., \& Ueda, K. (2016). Cyber-Physical Systems in Manufacturing. CIRP Annals, 65(2), 621-641.

Musikthong, C., \& Chutima, P. (2020). The Development of Machineries and Technologies to Support Digital Transformation. In Proceedings of the 2020 2nd International Conference on Management Science and Industrial Engineering, 7-9 April 2020, Osaka, Japan.

Nemec, B., Lenart, B., \& Zlajpah, L. (2003). Automation of Lasting Operation in Shoe Production Industry. In IEEE International Conference on Industrial Technology, 10-12 December 2003, Maribor, Slovenia.

Nowell, L. S., Norris, J. M., White, D. E., \& Moules, N. J. (2017). Thematic Analysis. International Journal of Qualitative Methods, 16(1). doi: $10.1177 / 1609406917733847$

Nwaiwu, F., Duduci, M., Chromjakova , F., \& Otekhile, C.A. F. (2020). Industry 4.0 concepts within the Czech
SME manufacturing sector: an empirical assessment of critical success factors. Business: Theory and Practice, 21(1), 58-70. doi: 10.3846/btp.2020.10712

Paulk, M. C., Curtis, B., Chrissis, M. B., \& Weber, C. V. (1993). Capability Maturity Model, Version 1.1. IEEE Software, 10(4), 18-27.

Perales D. P., Valero F. A., García A. B. (2018). Industry 4.0: A Classification Scheme. In E. Viles, M. Ormazábal, \& A. Lleó (Eds.), Closing the Gap Between Practice and Research in Industrial Engineering. Lecture Notes in Management and Industrial Engineering. Cham, Switzerland: Springer. doi: 10.1007/978-3-31958409-6_38

Peruzzini, M., Grandi, F., \& Pellicciari, M. (2017). Benchmarking of Tools for User Experience Analysis in Industry 4.0. Procedia Manufacturing, 11, 806-813.

Sadeghi, P., Rebelo, R. D., \& Ferreira, J. S. (2021). Using Variable Neighbourhood Descent and Genetic Algorithms for Sequencing Mixed-Model Assembly Systems in the Footwear Industry. Operations Research Perspectives, 8, 100193-100212. doi: 10.1016/j. orp.2021.100193

Schweer, D., \& Sahl, J. C. (2017). The Digital Transformation of Industry-The Benefit for Germany. In The Drivers of Digital Transformation (pp. 23-31). Cham, Switzerland: Springer.

Siderska, J. (2020). Robotic Process Automation - A Driver of Digital Transformation? Engineering Management in Production and Services, 12(2), 21-31. doi: 10.2478/emj-2020-0009

Stoldt, J., Trapp, T. U., Toussaint, S., Süße, M., Schlegel, A., \& Putz, M. (2018). Planning for Digitalisation in SMEs using Tools of the Digital Factory. Procedia CIRP, 72, 179-184.

Tran, M. D., Tran, T. H., Vu, D. T., \& Nguyen, T. C. (2021). Case Study: Prototyping a Low-Cost Integrated $\mathrm{Au}-$ tomation System in Footwear Industry for Small and Medium Enterprises in Vietnam. Proceedings of the 2nd Annual International Conference on Material, Machines and Methods for Sustainable Development (MMMS2020), 12-15 November 2020, Nha Trang, Vietnam.

Valenduc, G., \& Vendramin, P. (2017). Digitalisation, between Disruption and Evolution. Transfer: European Review of Labour and Research, 23(2), 121-134.

Vial, G. (2019). Understanding Digital Transformation: A Review and a Research Agenda. The Journal of Strategic Information Systems, 28(2), 118-144.

Vogelsang, K., Liere-Netheler, K., Packmohr, S., \& Hoppe, U. (2019). Success Factors for Fostering a Digital Transformation in Manufacturing Companies. Journal of Enterprise Transformation, 8(1-2), 121-142. doi: 10.1080/19488289.2019.1578839

Wright, P. (2014). Cyber-Physical Product Manufacturing. Manufacturing Letters, 2(2), 49-53.

Zangiacomi, A., Zhijian, L., Sacco, M., \& Boër, C. R. (2004). Process Planning and Scheduling for Mass Customised Shoe Manufacturing. International Journal of Computer Integrated Manufacturing, 17(7), 613-621.

Zhao, Z., Lin, P., Shen, L., Zhang, M., \& Huang, G. Q. (2020). IoT Edge Computing-Enabled Collaborative Tracking System for Manufacturing Resources 
in Industrial Park. Advanced Engineering Informatics, 43, 101044-101056. doi: 10.1016/j.aei.2020.101044101056

Zhang, Y., \& Sun, S. (2013). Real-time data driven monitoring and optimization method for IoT-based sensible production process. Proceeding of the 10th IEEE international conference on networking, sensing and control (ICNSC), 10-12 April 2013, Evry, France.

Zhong, R. Y., Dai, Q. Y., Qu, T., Hu, G. J., \& Huang, G. Q. (2013). RFID-enabled real-time manufacturing execution system for mass-customization production. Robotics and Computer-Integrated Manufacturing, 29(2), 283-292. 